\title{
Dependence of the sticking coefficient of sputtered atoms on the target-substrate distance
}

\author{
S Mahieu ${ }^{1,3}$, K Van Aeken ${ }^{1}$, D Depla ${ }^{1}$, D Smeets $^{2}$ and A Vantomme ${ }^{2}$ \\ ${ }^{1}$ Department for Solid State Sciences, Ghent University, Krijgslaan 281 (S1) 9000 Ghent, Belgium \\ ${ }^{2}$ Instituut voor Kern- en stralingsfysica \& INPAC, K.U. Leuven, Celestijnenlaan 200 D, 3001 Leuven, \\ Belgium \\ E-mail: stijn.mahieu@ugent.be, koen.vanaeken@ugent.be,diederik.depla@ugent.be, \\ dries.smeets@fys.kuleuven.be and andre.vantomme@fys.kuleuven.be
}

Received 16 May 2008, in final form 9 June 2008

Published 3 July 2008

Online at stacks.iop.org/JPhysD/41/152005

\begin{abstract}
A Ti target was mounted on a planar magnetron and sputtered in a mixture of Ar and $\mathrm{N}_{2}$, resulting in a flux of metallic Ti particles forming a TiN film on a substrate. The sticking coefficient of Ti was determined by comparing the Ti flux towards the substrate with the actual amount of deposited Ti particles, as determined by Rutherford backscattering spectrometry. It was observed that the sticking coefficient of Ti increases significantly with increasing target-substrate distance, but is to a lesser extent influenced by the $\mathrm{N}_{2}$ partial pressure.
\end{abstract}

Modelling thin film growth necessitates a knowledge of not only the flux, state, energy and direction of all particles towards the substrate but also of the sticking coefficient of all film forming particles. Reactive magnetron sputtering, i.e. sputtering a metallic target in a mixture of a noble gas (often Ar) and a reactive gas $\left(\mathrm{O}_{2}\right.$ or $\left.\mathrm{N}_{2}\right)$, is a commonly used technique to deposit oxides or nitrides. In an attempt to model the growth of these compounds, the flux of the metallic and reactive species towards the substrate and their sticking coefficients on it should be known. Many attempts to model or simulate the metal flux during sputtering have been described in the literature. These models are able to simulate the flux of metallic particles quite accurately, but often fail to predict the deposition rate or composition because of the absence of a reliable metallic sticking coefficient. Although it has been reported for a few examples that this sticking coefficient of sputtered metallic particles is material and temperature dependent and therefore not equal to unity [1-6], the sticking coefficient of these sputtered metallic particles is often assumed to be unity [7-9] since no better values are available or known. Hence,

\footnotetext{
${ }^{3}$ Postdoctoral Fellow of the Research Foundation-Flanders (FWO).
}

determining the metal sticking coefficient as a function of the deposition conditions is as important as modelling or simulating the flux of the film forming particles.

The effective sticking coefficient of sputtered $\mathrm{Ti}$ on $\mathrm{TiN}$ is defined as the ratio between the metallic Ti flux towards the substrate and the total number of deposited Ti atoms in the TiN film, i.e.

$$
S=\frac{F_{\mathrm{Ti}}}{\Theta_{\mathrm{Ti}}}
$$

with $\Theta_{\mathrm{Ti}}$ the total Ti flux towards the substrate and $F_{\mathrm{Ti}}$ the number of deposited $\mathrm{Ti}$ atoms, both typically expressed in atoms per square $\mathrm{cm}$ and per time unit (atoms $\mathrm{cm}^{-2} \mathrm{~s}^{-1}$ ). Here, the influence of the target-substrate distance $d_{\mathrm{T}-\mathrm{S}}$ on the sticking coefficient during reactive magnetron sputtering has been studied, as well as the influence of the $\mathrm{Ar} / \mathrm{N}_{2}$ gas flow ratio on this sticking coefficient.

Knowing the areal density of deposited atoms in TiN films, the number of Ti particles which actually stick, $F_{\mathrm{Ti}}$, can be determined. TiN films were deposited using a 2 in. Ti target which was sputtered in a mixture of $\mathrm{Ar}$ and $\mathrm{N}_{2}$. The total gas flow $(60 \mathrm{sccm})$, total pressure $(0.55 \mathrm{~Pa})$ and discharge current $I_{\mathrm{d}}(0.85 \mathrm{~A})$ were kept constant. The distance $d_{\mathrm{T}-\mathrm{S}}$ has been 
varied from 7 to $15 \mathrm{~cm}$, and the $\mathrm{N}_{2}$ flow from 6 to $12 \mathrm{sccm}$. The films were deposited on grounded $\mathrm{Si}$ substrates which were first chemically cleaned with a conventional RCA method and then in situ cleaned with a glow discharge. The RCA method includes a subsequent chemical cleaning for $10 \mathrm{~min}$ in three different boiling solutions $\left(\mathrm{H}_{2} 0: \mathrm{H}_{2} \mathrm{SO}_{4}: \mathrm{H}_{2} \mathrm{O}_{2}(3: 1: 1)\right.$; $\left.\mathrm{H}_{2} \mathrm{O}: \mathrm{HNO}_{3}: \mathrm{H}_{2} \mathrm{O}_{2} \quad(5: 1: 1) ; \mathrm{H}_{2} \mathrm{O}: \mathrm{HCl}: \mathrm{H}_{2} \mathrm{O}_{2} \quad(5: 1: 1)\right)$. After each solution, the sample is rinsed with deionized $\mathrm{H}_{2} \mathrm{O}$. The deposition time was adjusted to have a final TiN film thickness of $200-300 \mathrm{~nm}$. The actual number of Ti particles in the deposited TiN films, $N_{\mathrm{Ti}}$, is measured with Rutherford backscattering spectrometry (RBS). We used a $1.57 \mathrm{MeV} \mathrm{He}^{+}$ beam and detected the energy of the backscattered particles with a solid state detector placed at a backscattering angle of $168^{\circ}$. The absolute amount of deposited $\mathrm{Ti}$ atoms was determined from the integrated $\mathrm{Ti}$ signal, using the surface energy approximation and tabulated values for the stopping cross section of $\mathrm{He}^{+}$particles [10]. By dividing the number of Ti atoms $N_{\mathrm{Ti}}\left(\right.$ atoms $\mathrm{cm}^{-2}$ ) by the deposition time, $F_{\mathrm{Ti}}$ is determined.

In order to obtain the sticking coefficient (see equation (1)), the total Ti flux towards the substrate, $\Theta_{\mathrm{Ti}}$, was determined by a combination of binary collision Monte Carlo simulations and energy resolved mass spectrometer measurements.

The influence of the distance $d_{\mathrm{T}-\mathrm{S}}$ on the metallic Ti flux towards a substrate can be simulated by a binary collision Monte Carlo code as described in [11,12]. These Monte Carlo simulations were performed for sputtering a 2 in. planar Ti target in pure $\operatorname{Ar}(0.55 \mathrm{~Pa})$.

The total Ti flux $\Theta_{\mathrm{Ti}}$ (atoms $\mathrm{cm}^{2} \mathrm{~s}^{-1}$ ) towards the substrate is obtained by

$$
\Theta_{\mathrm{Ti}}=f Y \frac{I_{\mathrm{d}}}{(1+\gamma) e}
$$

in which $\gamma$ is the ion induced secondary electron emission coefficient of Ti (0.114 [13]), $Y$ the sputter yield of Ti due to Ar bombardment, $I_{\mathrm{d}}(\mathrm{A})$ the discharge current, $f$ the fraction of simulated Ti atoms that reaches the central square $\mathrm{cm}$ of the substrate and $e$ the elementary charge unit.

The sputter yield of Ti has been experimentally determined by sputtering a Ti target at constant discharge voltage $(365 \mathrm{~V})$ while logging the discharge current. From the measured weight loss, the number of sputtered $\mathrm{Ti}$ particles and thus also the sputter yield can be calculated. A sputter yield of $0.40 \pm 0.01$ was obtained, which compares well with the experimental and theoretical sputter yields reported by Yamamura and Tawara [14]. To verify the simulation results, the relative influence of $d_{\mathrm{T}-\mathrm{S}}$ on the flux of metallic Ti particles sputtered in pure Ar from a Ti target has also been measured by means of a water cooled and plasma shielded thickness monitor.

As shown in figure 1, the simulations correspond quite well with the experiments and both methods show that the metallic flux decreases more or less with a $1 /\left(d_{\mathrm{T}-\mathrm{S}}\right)^{2}$ rule.

To study the relative influence of the $\mathrm{N}_{2}$ flow on $\Theta_{\mathrm{Ti}}$ an energy resolved mass spectrometer was installed at the substrate position [15]. Due to a too low (and unknown) sensitivity of the mass spectrometer for fast neutrals, the signal

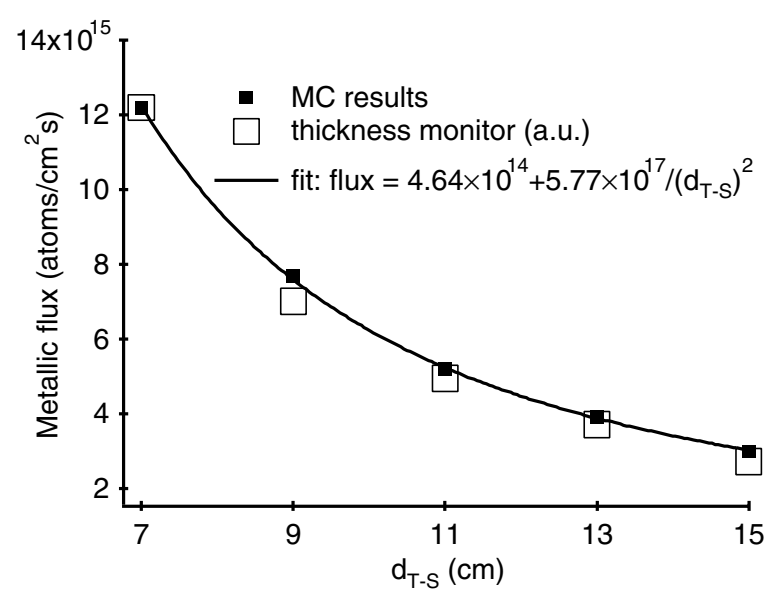

Figure 1. Influence of the distance $d_{\mathrm{T}-\mathrm{S}}$ on the metallic flux as simulated with the MC code (filled symbols) and as measured with the thickness monitor (open symbols, in arbitrary units).

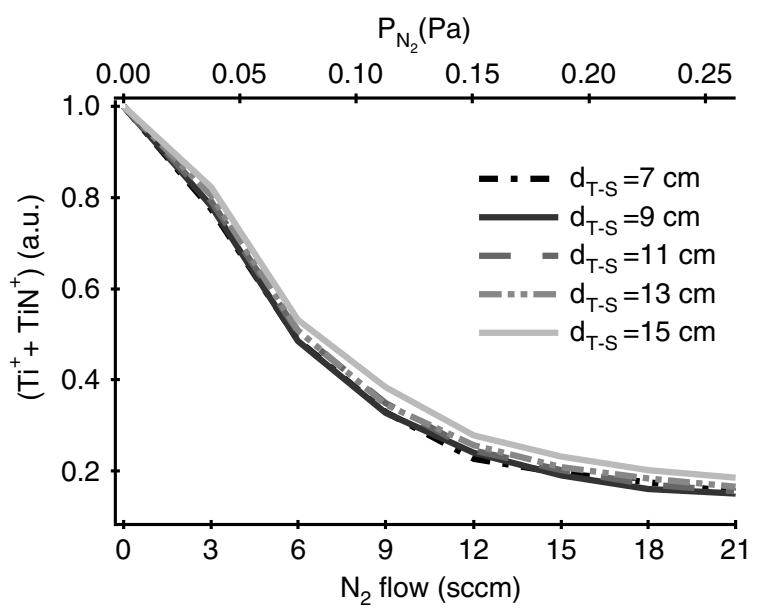

Figure 2. Influence of the $\mathrm{N}_{2}$ flow and $\mathrm{N}_{2}$ partial pressure on the metallic flux measured with the energy resolved mass spectrometer.

of positive ions with a mass of $48 \mathrm{amu}\left(\mathrm{Ti}^{+}\right)$and $62 \mathrm{amu}\left(\mathrm{TiN}^{+}\right)$ was measured. Since the ionization degree is hardly influenced by the $\mathrm{N}_{2}$ flow, as was checked by a cylindrical Langmuir probe and a retarding field energy analyzer, the influence of the $\mathrm{N}_{2}$ flow on the normalized incoming $\left(\mathrm{Ti}^{+}+\mathrm{TiN}^{+}\right)$flux is assumed to be equal to its influence on the normalized $(\mathrm{Ti}+\mathrm{TiN})$ flux towards the substrate. As seen in figure 2 , the metallic flux is strongly decreasing with increasing $\mathrm{N}_{2}$ flow, but the relative influence of the $\mathrm{N}_{2}$ flow on the metallic flux is similar for all target-substrate distances. The decrease in the metallic flux with increasing $\mathrm{N}_{2}$ flow is mainly due to target poisoning $[13,16,17]$ and due to the lower sputter yield of $\mathrm{N}^{+}$ions compared with $\mathrm{Ar}^{+}$ions. The energy resolved mass spectrometer measurements also showed that the TiN/Ti ratio is at maximum 0.04 .

Combination of the binary collision Monte Carlo simulations (influence of $d_{\mathrm{T}-\mathrm{S}}$ ) and the energy resolved mass spectrometer measurements (influence of the $\mathrm{N}_{2}$ flow) allows us to calculate the metallic Ti flux towards the substrate $\Theta_{\mathrm{Ti}}$ as a function of the distance $d_{\mathrm{T}-\mathrm{S}}$ and the $\mathrm{N}_{2}$ flow.

In the previous paragraphs both $\Theta_{\mathrm{Ti}}$, the total $\mathrm{Ti}$ flux towards the substrate, and $F_{\mathrm{Ti}}$ the number of deposited $\mathrm{Ti}$ 


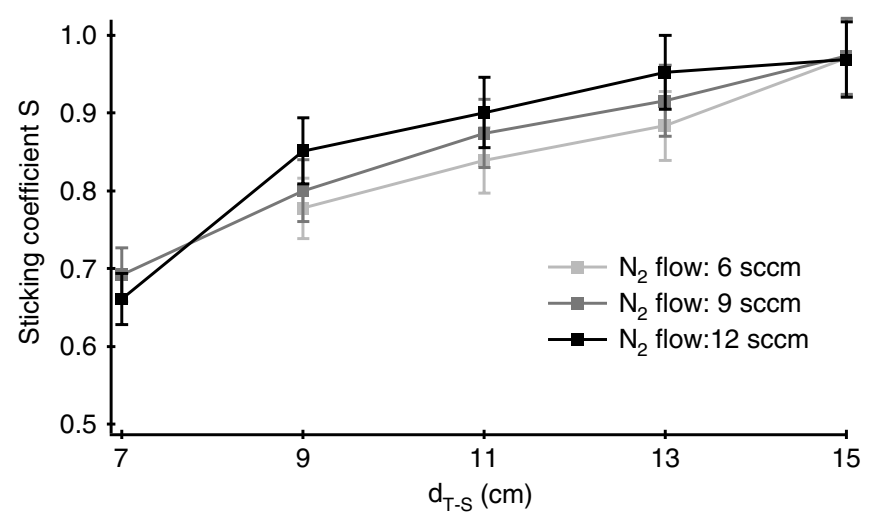

Figure 3. Influence of the distance $d_{\mathrm{T}-\mathrm{S}}$ and the $\mathrm{N}_{2}$ flow on the calculated sticking coefficients of $\mathrm{Ti}$ on $\mathrm{TiN}$.

atoms per square $\mathrm{cm}$ and per time unit (atoms $\mathrm{cm}^{-2} \mathrm{~s}^{-1}$ ) were determined. Equation (1) enables us to calculate the sticking coefficient $\mathrm{S}$ of $\mathrm{Ti}$ on $\mathrm{TiN}$ as a function of the studied experimental conditions. Due to a small variation of the metallic flux with target erosion an error of $5 \%$ on the calculated values should be taken into account, as shown in figure 3 .

Data about sticking coefficients of sputtered atoms are scarce in the literature. Libbrecht et al reported that the sticking coefficient of sputtered $\mathrm{U}$ atoms on $\mathrm{Al}_{2} \mathrm{O}_{3}$ increases from 0.9 to nearly 1.0 when the energy of the sputtered particles exceeds $10 \mathrm{eV}$ [18]. Bogaerts et al have reported that the simulated density profile of Ta fitted well with experimental profiles, when assuming a sticking coefficient of 0.5 [1]. On the other hand, the same authors reported values of $0.02-0.2$ for sputtered Li atoms, depending on the conditions [2]. Nafarizal and Sasaki measured the sticking coefficient of $\mathrm{Ti}$ on $\mathrm{Ti}$ and obtained a value of $0.9 \pm 22 \%$ [6]. Probably due to the large error on their measurements, they could not find a variation in this sticking coefficient with changing pressure, discharge power or substrate temperature.

Figure 3 shows that the sticking coefficient $S$ is slightly decreasing with decreasing $\mathrm{N}_{2}$ flow, but this observation is within the uncertainty of the measurements. However, it is observed in figure 3 that the sticking coefficient decreases from 1 to 0.65 with decreasing target-substrate distance. Such a decrease in the effective sticking coefficient of sputtered metallic particles can be caused by resputtering, reflection or thermal desorption. The possible influence of these three processes are discussed below.

Some ions which are accelerated towards the target will be neutralized and reflected at the target. As such, these particles can then hit the growing film with a considerable high energy and cause resputtering. Of course, resputtering results in a lowering of the effective sticking coefficient. However, the decreasing sticking coefficient with decreasing $d_{\mathrm{T}-\mathrm{S}}$, as seen in figure 3, cannot be caused by an increased resputtering, since one would expect the same effect during the thickness monitor measurements. As seen in figure 1, the metallic flux as measured with the thickness monitor is equal to the simulated metallic flux, giving evidence that the sticking coefficient on the TiN coated oscillating quartz crystal of the thickness monitor is not influenced by the target-substrate distance, and thus not affected by resputtering.

According to Zhou and Wadley, the reflection coefficient of sputtered particles is almost zero for low energy particles $(E<25 \mathrm{eV})$ [19]. Only for energetic particles $(E>25 \mathrm{eV})$ that hit the surface at a large angle is the reflection coefficient no longer negligible. It could be calculated with the abovementioned binary collision Monte Carlo simulation code that the energy of the incoming sputtered particles is always below $25 \mathrm{eV}$ [11] and that the incoming direction of the sputtered particles is nearly independent of $d_{\mathrm{T}-\mathrm{S}}$ [20]. As such, reflection of Ti species can be excluded as a possible process causing the noticed trend of the sticking coefficient as a function of the target-substrate distance.

Finally, the effective sticking coefficient can also be influenced by the surface temperature of the substrate. A higher surface temperature will induce a higher desorption rate, lowering the effective sticking coefficient. Our depositions were performed on Si substrates which were not cooled, nor heated. Hence, the actual surface temperature of the growing film will be determined by the total energy flux towards the substrate during sputtering. This total energy flux increases with decreasing $d_{\mathrm{T}-\mathrm{S}}$ [21]. Hence, increasing desorption with decreasing $d_{\mathrm{T}-\mathrm{S}}$ can be expected, resulting in a decreasing effective sticking coefficient with decreasing $d_{\mathrm{T}-\mathrm{S}}$.

It can be concluded that the sticking coefficient of metallic particles is not always (close to) unity and should be verified experimentally for the used deposition conditions. In the specific case of $\mathrm{Ti}$ on $\mathrm{TiN}$, a decrease from 1.00 to 0.65 of the sticking coefficient with decreasing target-substrate distance is shown. This trend can be explained by an increased desorption effect that is most probably related to a difference in energy flux to the substrate with different target-substrate distances. Since the energy flux, and thus the desorption rate, strongly depends on the used deposition conditions, knowledge of this energy flux and its relation to the sticking coefficient is of fundamental importance to model the growth of thin films.

\section{References}

[1] Bogaerts A, Wagner E, Smith B W, Winefordner J D, Pollmann D, Harrison W W and Gijbels R 1997 Spectrochim. Acta. B $\mathbf{5 2} 205$

[2] Bogaerts A, Naylor J, Hatcher M, Jones J and Mason R 1998 J. Vac. Sci. Technol. A 162400

[3] Emmoth B and Bergsaker H 1988 Nucl. Instrum. Methods B 33435

[4] Theirich D and Engemann J 1991 Nucl. Instrum. Methods B 59-60 336

[5] Yamazaki O, Iyanagi K, Takagi S and Nanbu K 2002 Japan J. Appl. Phys. 411230

[6] Nafarizal N and Sasaki N 2007 J. Vac. Sci. Technol. A 25308

[7] Yagisawa T and Makabe T 2006 J. Vac. Sci. Technol. A 24908

[8] Bauer W, Betz G, Bangert H, Bergauer A and Eisenmenger-Sittner C 1996 Thin Solid Films 281-282 68

[9] Motohiro T 1986 J. Vac. Sci. Technol. A 4189

[10] Chu W K, Mayer J W and Nicolet M A 1978 Backscattering Spectrometry (New York: Academic)

[11] Mahieu S, Buyle G, Depla D, Heirwegh S, Ghekiere P and De Gryse R 2006 Nucl. Instrum. Methods B 243313 
IOP FTC

[12] Mahieu S, Van Aeken K and Depla D 2008 Reactive Sputter Deposition ed D Depla and S Mahieu (Berlin: Springer) chapter 6

[13] Depla D, Mahieu S and De Gryse R 2008 Reactive Sputter Deposition ed D Depla and S Mahieu (Berlin: Springer) chapter 5

[14] Yamamura Y and Tawara T 1996 At. Data Nucl. Data Tables 62149

[15] Mahieu S, Depla D and De Gryse R 2008 Surf. Coat. Technol. 2022314
[16] Depla D, Heirwegh S, Mahieu S, Haemers J and De Gryse R 2007 J. Appl. Phys. 101013301

[17] Berg S and Nyberg T 2005 Thin Solid Films 476215

[18] Libbrecht K G, Griffith J E, Weller R A and Tombrello T A 1980 Radiat. Eff. Defects Solids 49195

[19] Zhou X W and Wadley H N G 1999 Surf. Sci. 43158

[20] Mahieu S, Ghekiere P, Depla D and De Gryse R 2006 Thin Solid Films 5151229

[21] Ekpe S D and Dew S K 2004 J. Vac. Sci. Technol. A 221420 